\title{
Histone Deacetylase Inhibitors Downregulate Calcium Pyrophosphate Crystal Formation in Human Articular Chondrocytes
}

\author{
Chi-Ching Chang ${ }^{1,2} \mathbb{D}$, Kun-Lin Lee ${ }^{3,4}$, Tze-Sian Chan ${ }^{5,6} \mathbb{D}$, Chia-Chen Chung ${ }^{3,4}$ and Yu-Chih Liang ${ }^{3,4,7,8, *(\mathbb{D})}$
}

Citation: Chang, C.-C.; Lee, K.-L.; Chan, T.-S.; Chung, C.-C.; Liang, Y.-C. Histone Deacetylase Inhibitors Downregulate Calcium

Pyrophosphate Crystal Formation in Human Articular Chondrocytes. Int. J. Mol. Sci. 2022, 23, 2604. https:// doi.org/10.3390/ijms23052604

Academic Editor: Zsuzsanna Helyes

Received: 29 January 2022

Accepted: 24 February 2022

Published: 26 February 2022

Publisher's Note: MDPI stays neutral with regard to jurisdictional claims in published maps and institutional affiliations.

Copyright: (C) 2022 by the authors. Licensee MDPI, Basel, Switzerland. This article is an open access article distributed under the terms and conditions of the Creative Commons Attribution (CC BY) license (https:// creativecommons.org/licenses/by/ $4.0 /)$.
1 Division of Allergy, Immunology and Rheumatology, Department of Internal Medicine, School of Medicine, College of Medicine, Taipei Medical University, Taipei 11031, Taiwan; ccchang@tmu.edu.tw

2 Division of Rheumatology, Immunology and Allergy, Department of Internal Medicine, Taipei Medical University Hospital, Taipei 11031, Taiwan

3 School of Medical Laboratory Science and Biotechnology, College of Medical Science and Technology, Taipei Medical University, Taipei 11031, Taiwan; kunlinleetw@gmail.com (K.-L.L.); shettoangel@gmail.com (C.-C.C.)

4 Ph.D. Program in Medical Biotechnology, College of Medical Science and Technology, Taipei Medical University, Taipei 11031, Taiwan

5 Division of Gastroenterology, Department of Internal Medicine, School of Medicine, College of Medicine, Taipei Medical University, Taipei 11031, Taiwan; fzesian@tmu.edu.tw

6 Division of Gastroenterology, Department of Internal Medicine, Wan Fang Hospital, Taipei 11696, Taiwan

7 Ph.D. Program in Drug Discovery and Development Industry, College of Pharmacy, Taipei Medical University, Taipei 11031, Taiwan

8 Traditional Herbal Medicine Research Center, Taipei Medical University Hospital, Taipei 11031, Taiwan

* Correspondence: ycliang@tmu.edu.tw

\begin{abstract}
Calcium pyrophosphate (CPP) deposition disease (CPPD) is a form of CPP crystal-induced arthritis. A high concentration of extracellular pyrophosphate (ePPi) in synovial fluid is positively correlated with the formation of CPP crystals, and ePPi can be upregulated by ankylosis human (ANKH) and ectonucleotide pyrophosphatase 1 (ENPP1) and downregulated by tissue non-specific alkaline phosphatase (TNAP). However, there is currently no drug that eliminates CPP crystals. We explored the effects of the histone deacetylase (HDAC) inhibitors (HDACis) trichostatin A (TSA) and vorinostat (SAHA) on CPP formation. Transforming growth factor (TGF)- $\beta 1$-treated human primary cultured articular chondrocytes (HC-a cells) were used to increase ePPi and CPP formation, which were determined by pyrophosphate assay and CPP crystal staining assay, respectively. Artificial substrates thymidine $5^{\prime}$-monophosphate p-nitrophenyl ester (p-NpTMP) and p-nitrophenyl phosphate (p-NPP) were used to estimate ENPP1 and TNAP activities, respectively. The HDACis TSA and SAHA significantly reduced mRNA and protein expressions of ANKH and ENPP1 but increased TNAP expression in a dose-dependent manner in HC-a cells. Further results demonstrated that TSA and SAHA decreased ENPP1 activity, increased TNAP activity, and limited levels of ePPi and CPP. As expected, both TSA and SAHA significantly increased the acetylation of histones 3 and 4 but failed to block Smad- 2 phosphorylation induced by TGF- $\beta 1$. These results suggest that HDACis prevented the formation of CPP by regulating ANKH, ENPP1, and TNAP expressions and can possibly be developed as a potential drug to treat or prevent CPPD.
\end{abstract}

Keywords: calcium pyrophosphate; HDAC; ANKH; ENPP1; TNAP

\section{Introduction}

Calcium pyrophosphate (CPP) deposition disease (CPPD) is a manifestation of the abnormal accumulation of CPP crystals in a joint. The main risk factor for CPPD is aging, and $75 \%$ of acute patients are aged over 85 years [1]. Symptoms of CPPD include inflammation and cartilage degeneration, which are similar to a gout attack; therefore, this 
condition is also called pseudogout [2]. Extracellular pyrophosphate (ePPi), calcium, and extracellular matrix (ECM) are essential components of CPP crystal formation [3]. In CPPD patients, a high concentration of ePPi in the synovial fluid is mainly locally produced in joints [4]. Many diseases are characterized by high levels of ePPi in synovial fluid, including osteoarthritis (OA) with CPPD [5], hyperparathyroidism [6], hypomagnesemia [7], and hemochromatosis [8]. The ePPi in synovial fluid originates from ATP hydrolysis by ectonucleotide pyrophosphatase 1 (ENPP1, also known as phosphodiesterase family member 1 (PC-1)) $[9,10]$ or efflux from the cytosol by the diphosphate transmembrane transporter, ANKH [11]. Otherwise, ePPi can be cleaved into phosphate by tissue non-specific alkaline phosphatase (TNAP, also called alkaline phosphatase, liver (ALPL)) [12].

Previous studies found that mutations or single-nucleotide polymorphisms of the $A N K H$ gene may increase the function of $\mathrm{ANKH}$, leading to increased ePPi levels and CPPD incidence [13]. In addition to efflux of PPi, ANKH exports ATP to the extracellular space, which may increase the cleavage of ATP into PPi [14]. The concentration of ePPi is mainly regulated by several growth factors and cytokines, including transforming growth factor (TGF)- $\beta[13,15]$, interleukin (IL)-1 $\beta$ [16], and insulin-like growth factor (IGF)-1 [14]. Other factors were also found to promote the formation of CPP crystals, such as type 2 transglutaminase [17,18], coagulation factor XIIIa [19], and osteopontin [20]. TGF- $\beta$ increases the activities of PC-1, ANKH, cartilage intermediate layer protein (CILP), and transglutaminase and reduces the activity of TNAP, ultimately upregulating the level of ePPi [13,15]. Conversely, IGF-1 and inflammatory cytokines (such as IL-1 $\beta$ ) can lead to lower ePPi levels [14].

In epigenetics, histone acetylation and DNA methylation were shown to play key roles in regulating gene expressions and cell functions [21]. Two different groups of enzymes, namely histone acetyltransferases (HATs) and histone deacetylases (HDACs), are responsible for regulation of acetylation and deacetylation, respectively [22]. Besides histones, some non-histone proteins can also be modified by HDACs $[23,24]$. The acetylation of various kinds of proteins was shown to play roles in a variety of cellular processes, such as gene expression, chromatin remodeling, splicing, nuclear transport, cell cycle progression, actin polymerization, and DNA damage repair, as well as the functions of the cytoskeleton, chaperones, and ribosomes [25].

HDAC inhibitors (HDACis) accelerate osteoblast differentiation but reduce osteoclastogenesis [26]. Studies have also confirmed that HDAC plays a critical role in maintaining the balance between osteoblast bone formation and osteoclast bone resorption [27]. HDACis can promote the process of osteogenic differentiation, expressions of osteoblast-related genes, and the formation of bone nodules [28]. In a mouse experiment of skull defects, pre-osteoblasts pretreated with an HDACi exhibited enhanced bone regeneration [29], which demonstrated that HDAC is an important epigenetic factor driving mineral tissue regeneration.

In macrophages, CPP crystals can activate the inflammasome via the NLR family pyrin domain-containing 3 (NLRP3) and induce the production of the pro-inflammatory factor IL-1 $\beta$, which in turn stimulates the production of other cytokines, such as tumor necrosis factor (TNF)- $\alpha$ to amplify the inflammatory response [30]. CPP crystals can also cause nitric oxide (NO) production through the Toll-like receptor 2 (TLR2) pathway in chondrocytes [31]. In addition, CPP crystals inhibit neutrophil apoptosis and stimulate neutrophils to release myeloperoxidase, IL-1 $\beta$, IL-8, IL-6, and neutrophil extracellular traps (NETs) and then cause damage to bystander cells and tissues [32].

At present, many treatments are available to improve symptoms, but they cannot cure CPPD; these include colchicine, hydroxychloroquine, non-steroidal anti-inflammatory drugs (NSAIDs), corticosteroids, and anakinra [33-36]. Once CPP crystals are deposited, they can only be removed by drawing out the synovial fluid. Therefore, preventing CPP crystal formation is a preferable strategy against CPPD. In this study, we investigated the roles of the HDACis trichostatin A (TSA) and vorinostat (SAHA) in preventing CPP crystal formation using primary cultured human articular chondrocytes (HC-a cells) in a TGF- $\beta 1$ 
model. We found that both TSA and SAHA decreased CPP formation by downregulating ENPP1 and ANKH and upregulating TNAP gene expressions independent of the TGF- $\beta 1$ induced Smad signal pathway.

\section{Results}

\subsection{HDACis Downregulated ANKH and ENPP1 Expressions and Upregulated TNAP Expression}

It is known that HDACis can regulate gene expressions by changing epigenetic modifications. To understand whether HDACis can regulate CPPD-related gene expressions, we used primary cultured human articular chondrocytes (HC-a cells) and two HDACis, TSA and SAHA. As mentioned in the Introduction, high levels of ANKH and ENPP1 promote CPP crystal formation, whereas TNAP reduces CPP crystal formation. TSA significantly decreased mRNA expressions of ANKH and ENPP1 but increased TNAP mRNA expression in dose-dependent manners compared to TGF- $\beta 1$-treated cells (Figure 1A). Western blot analysis also demonstrated that TSA dose-dependently inhibited protein expressions of ANKH and ENPP1 but increased TNAP expression (Figure 1B). On the other hand, SAHA exhibited similar trends of inhibiting both $A N K H$ and ENPP1 expression and increasing TNAP expression. Compared to TGF- $\beta 1$ treatment, $100-1000$ nM of SAHA significantly decreased $A N K H$ and increased ENPP1 mRNA expression, but lower concentrations of SAHA (10-100 nM) inhibited ENPP1 mRNA expression (Figure 2A). Again, a similar trend of protein levels was found by a Western blot analysis (Figure 2B). These results suggest that both HDACis, TSA and SAHA, were able to inhibit expression of ANKH and ENPP1 but increased TNAP expression.
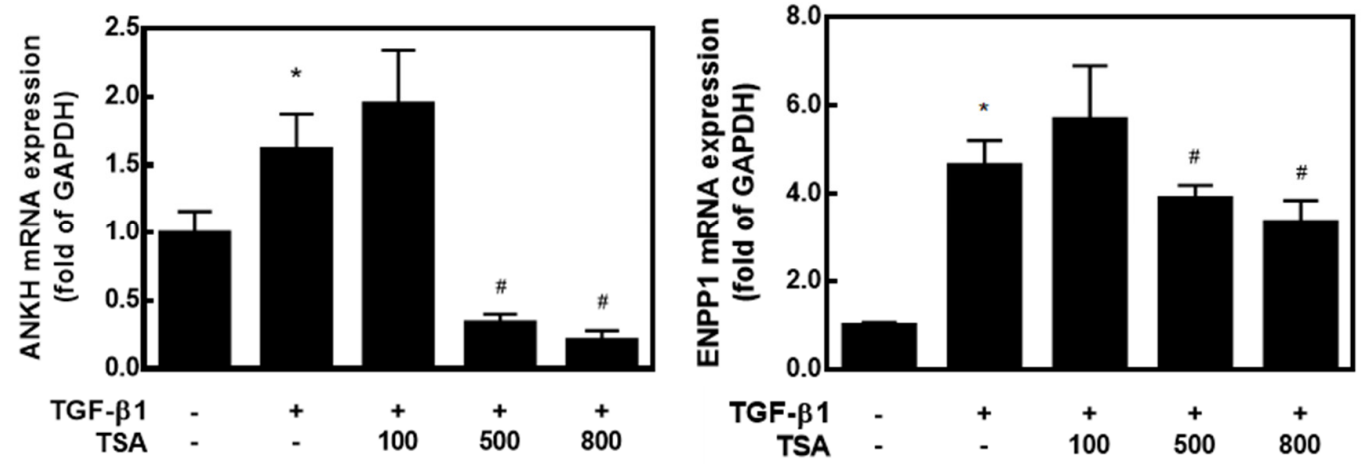

(A)
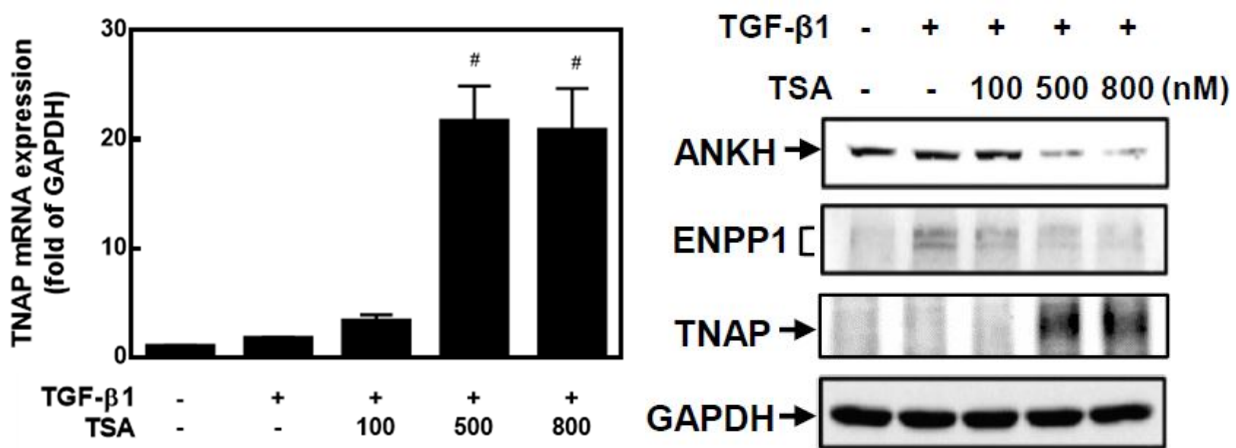

(B)

Figure 1. Trichostatin A (TSA) changed the calcium pyrophosphate (CPP)-related gene expressions in transforming growth factor (TGF)- $\beta 1$-treated chondrocytes. Human primary chondrocytes (HC-a cells) were pretreated with different concentrations of TSA (100-800 nM) for $30 \mathrm{~min}$ and then treated with $5 \mathrm{ng} / \mathrm{mL}$ TGF- $\beta 1$ for $24 \mathrm{~h}$. (A) Total RNAs were extracted, and mRNA expression levels of $A N K H, E N P P 1$, and TNAP were determined by real-time PCR. Data are expressed as the mean $\pm \mathrm{SE}$ of five independent experiments. ${ }^{*} p<0.05$ vs. column 1 ; $\# p<0.05$ vs. column 2 . (B) Total cellular proteins were collected, and protein expressions were detected by Western blotting. 

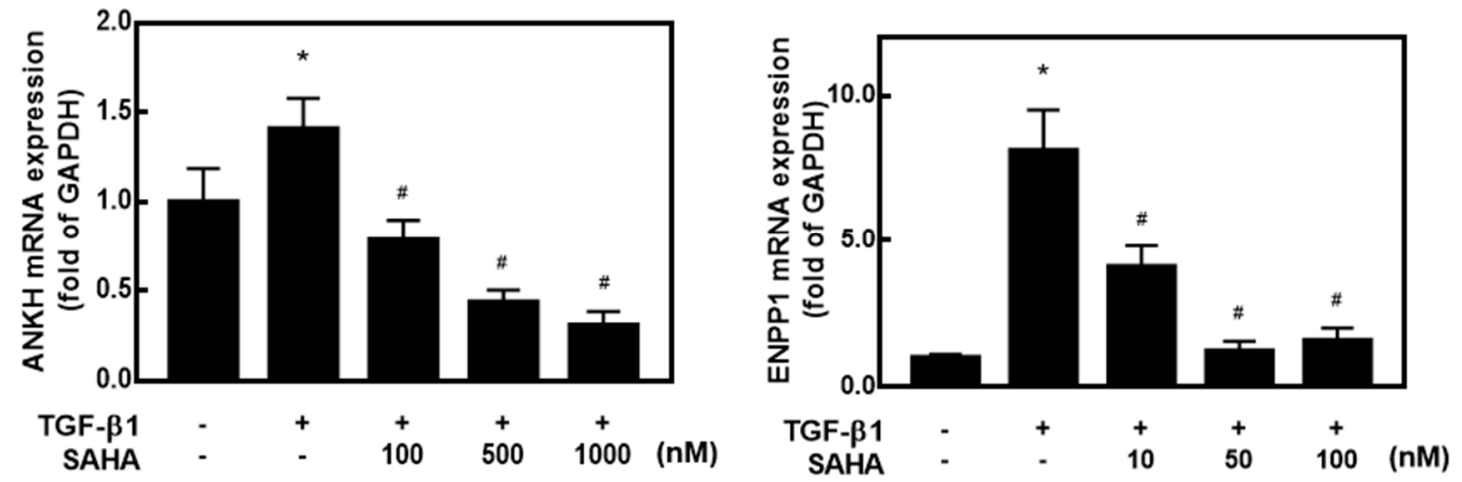

(A)
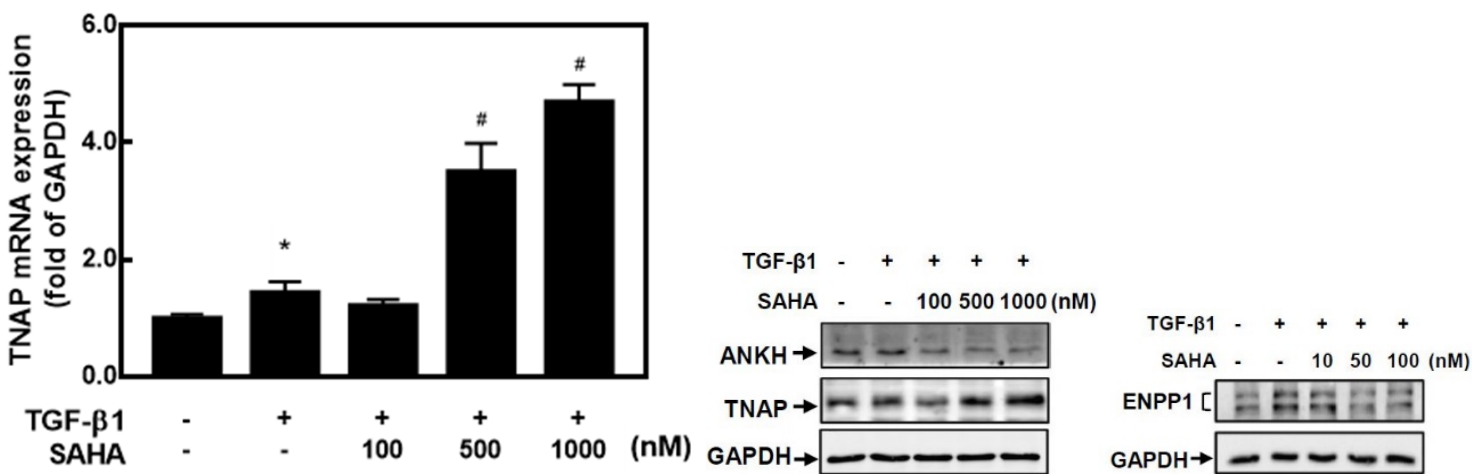

(B)

Figure 2. Vorinostat (SAHA) changed calcium pyrophosphate (CPP)-related gene expressions in transforming growth factor (TGF)- $\beta 1$-treated chondrocytes. Human primary chondrocytes (HC-a cells) were pretreated with different concentrations of SAHA (10-1000 nM) for 30 min and then treated with $5 \mathrm{ng} / \mathrm{mL}$ TGF- $\beta 1$ for $24 \mathrm{~h}$. (A) Total RNAs were extracted, and mRNA expression levels of $A N K H, E N P P 1$, and TNAP were determined by real-time PCR. Data are expressed as the mean $\pm \mathrm{SE}$ of at least four independent experiments. ${ }^{*} p<0.05$ vs. column 1 ; $\# p<0.05$ vs. column 2 . (B) Total cellular proteins were collected, and protein expressions were detected by Western blotting.

\subsection{HDACis Significantly Downregulated ENPP1 and Upregulated TNAP Activities in $\mathrm{HC}-a$ Cells}

Since HDACis can regulate CPP-related gene and protein expressions, we next examined whether HDACis could change CPP-related enzyme activities in cells using two artificial substrates: p-NpTMP for ENPP1 activity and p-NPP for TNAP activity. Both enzyme reactions produce the same end product, called p-NP ( $\mathrm{p}$-nitrophenol), which can be detected at OD410 $\mathrm{nm}$ by a spectrophotometer. HC-a cells were treated with different concentrations of HDACis for $24 \mathrm{~h}$, and then total cell lysates were collected to determine the cellular enzyme activities of ENPP1 and TNAP. As shown in Figure 3, TSA dosedependently downregulated ENPP1 activity and upregulated TNAP activity in a cell assay. In addition, SAHA significantly upregulated TNAP activity at a concentration of $500 \mathrm{nM}$ but downregulated ENPP1 at a lower concentration of $50 \mathrm{nM}$. These results suggest that both HDACis, TSA and SAHA, downregulated ENPP1 enzyme activity and upregulated TNAP enzyme activity by decreasing ENPP1 protein expression and increasing TNAP protein expression, respectively. 

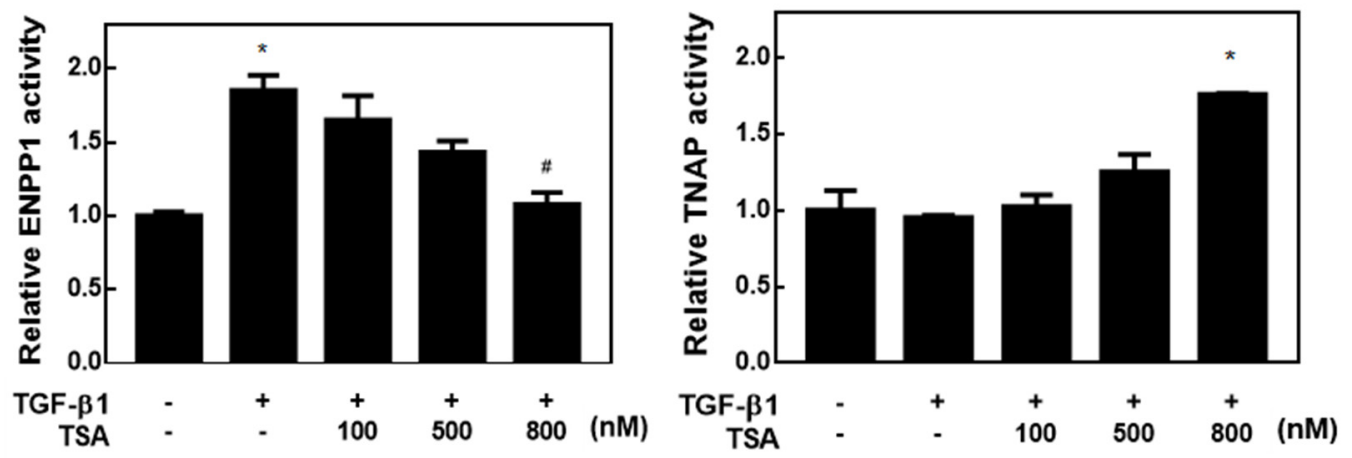

(A)
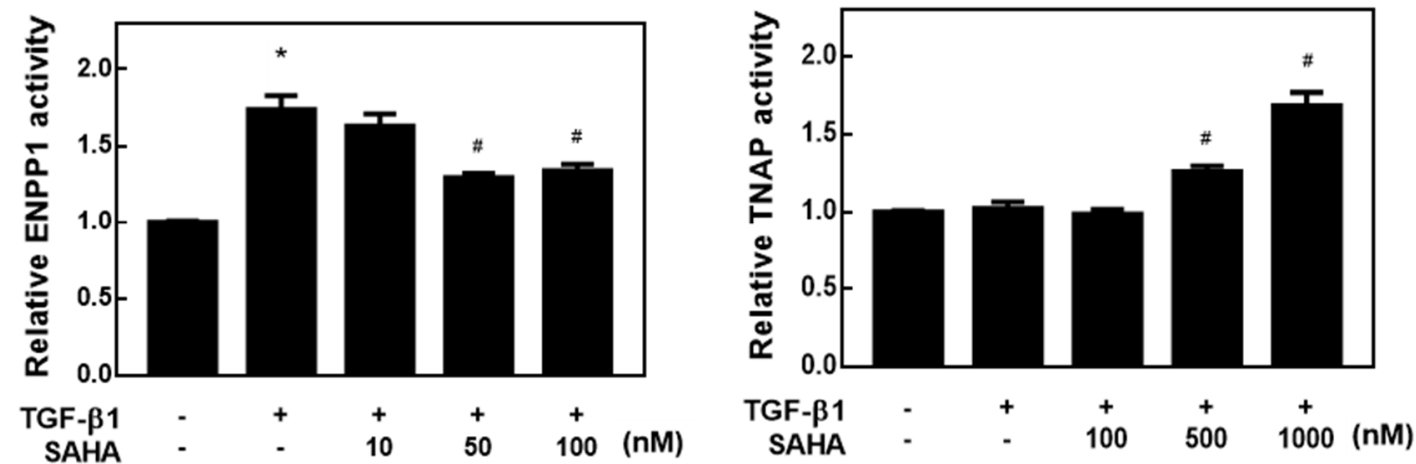

(B)

Figure 3. Histone deacetylase inhibitors (HDACis) decreased ectonucleotide pyrophosphatase 1 (ENPP1) activity and increased tissue non-specific alkaline phosphatase (TNAP) activity in transforming growth factor (TGF)- $\beta 1$-treated chondrocytes. (A,B) Human primary chondrocytes (HC-a cells) were pretreated with different concentrations of trichostatin A (TSA) (100 800 nM) and vorinostat (SAHA) (100-1000 nM) for $30 \mathrm{~min}$ and then treated with $5 \mathrm{ng} / \mathrm{mL}$ TGF- $\beta 1$ for $48 \mathrm{~h}$. Total cellular lysates were collected to determine ENPP1 and TNAP activities as described in Materials and Methods. Data are expressed as the mean \pm SE of at least three independent experiments. ${ }^{*} p<0.05$ vs. column 1 ; $\# p<0.05$ vs. column 2 .

\subsection{HDACis Downregulated Extracellular Pyrophosphate Levels and Prevented CPP Crystal Formation}

Since we found that HDACis could regulate ENPP1 and TNAP gene expressions and enzyme activities, we next examined whether the HDACis could decrease ePPi levels and CPP crystal formation in a cell model. As shown in Figure 4A, both TSA and SAHA significantly reduced the ePPi level in TGF- $\beta 1$-treated HC-a cells. ARS dye was applied to stain calcium deposits in HC-a cells. Then, the dye was extracted, and the concentration was measured by spectrophotometry. Both TSA and SAHA significantly decreased ARS dye levels in TGF- $\beta 1$-treated HC-a cells (Figure 4). The results suggest that the HDACis, TSA and SAHA, downregulated ePPi and ultimately decreased CPP crystal formation. 

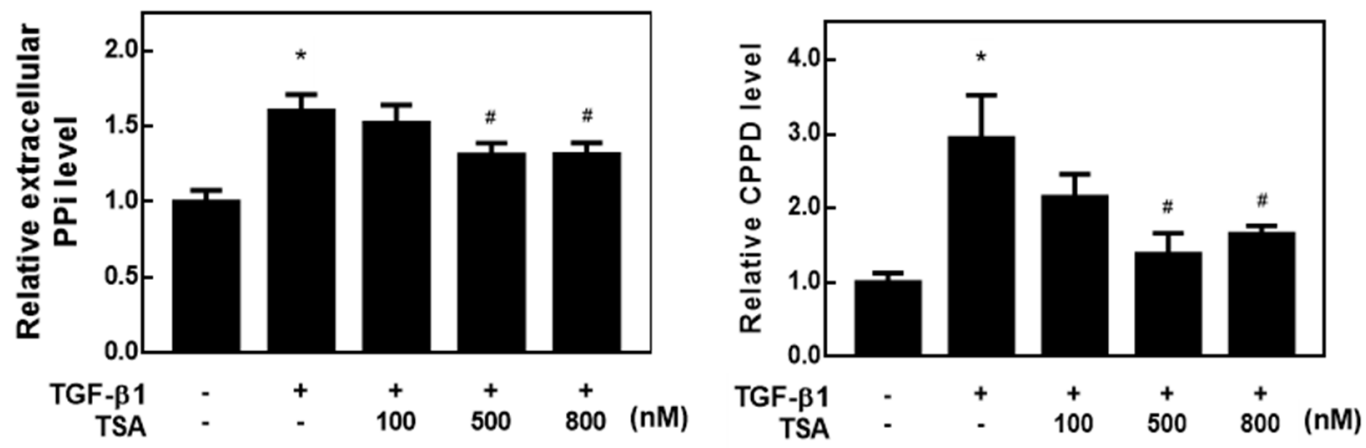

(A)
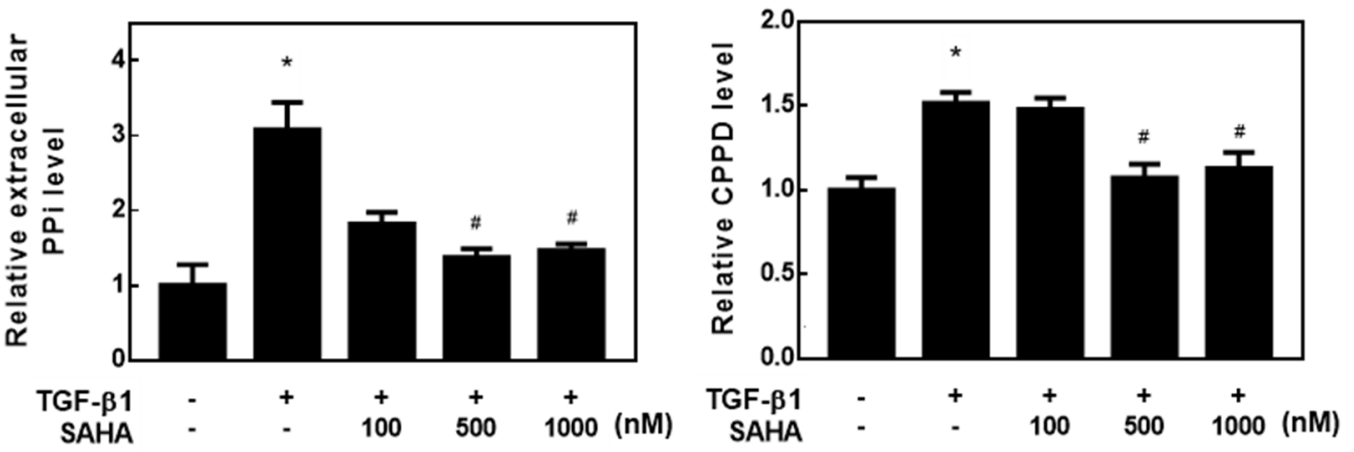

(B)

Figure 4. Histone deacetylase inhibitors (HDACis) decreased extracellular pyrophosphate levels and inhibited calcium pyrophosphate (CPP) crystal formation in transforming growth factor (TGF)$\beta 1$-treated chondrocytes. (A,B) Human primary chondrocytes (HC-a cells) were pretreated with different concentrations of trichostatin A (TSA) (100 800 nM) and vorinostat (SAHA) (100 1000 nM) for $30 \mathrm{~min}$ and then treated with $5 \mathrm{ng} / \mathrm{mL}$ TGF- $\beta 1$ for (A) 2 and (B) 5 days. Cultured medium and cells were used to determine the pyrophosphate (PPi) level and CPP crystal formation, respectively. Data are expressed as the mean $\pm \mathrm{SE}$ of at least three independent experiments. ${ }^{*} p<0.05$ vs. column $1 ; \# p<0.05$ vs. column 2.

\subsection{HDACis Increased the Acetylation of Histones $\mathrm{H} 3$ and $\mathrm{H} 4$}

To understand whether the HDACis could increase levels of histone acetylation and change CPP formation-related gene expressions, we examined acetylation levels of histones $\mathrm{H} 3$ and $\mathrm{H} 4$ and protein expressions of class I and II HDACs in HC-a cells. As shown in Figure 5A, both TSA and SAHA significantly induced the acetylation of histones $\mathrm{H} 3$ and $\mathrm{H} 4$ in dose-dependent manners. In addition, neither TSA nor SAHA changed the protein expressions of class I HDACs (HDAC1, 2, and 3), but both dose-dependently decreased HDAC7 expression (Figure 5B). However, TSA and SAHA had inconsistent effects on HDAC4, 5, and 7 protein expressions. TSA dose-dependently decreased these HDAC expressions, but SAHA slightly increased their expressions in the concentration range of $100-500 \mathrm{nM}$. As it is known that ANKH and ENPP1 can be induced by TGF- $\beta 1$, we next examined whether the HDACis regulated CPP formation-related gene expressions by blocking the TGF- $\beta 1$ signal pathway. Smad 2 phosphorylation and Smad 4 expression are major mediators in the TGF- $\beta 1$ canonical pathway. However, neither TSA nor SAHA inhibited Smad 2 phosphorylation or Smad 4 expression (Figure 6). The results suggest that the increases in histone acetylation by TSA and SAHA might be mediated through inhibition of HDAC enzyme activities and decreases in some HDAC protein expressions in a Smad-independent manner. 

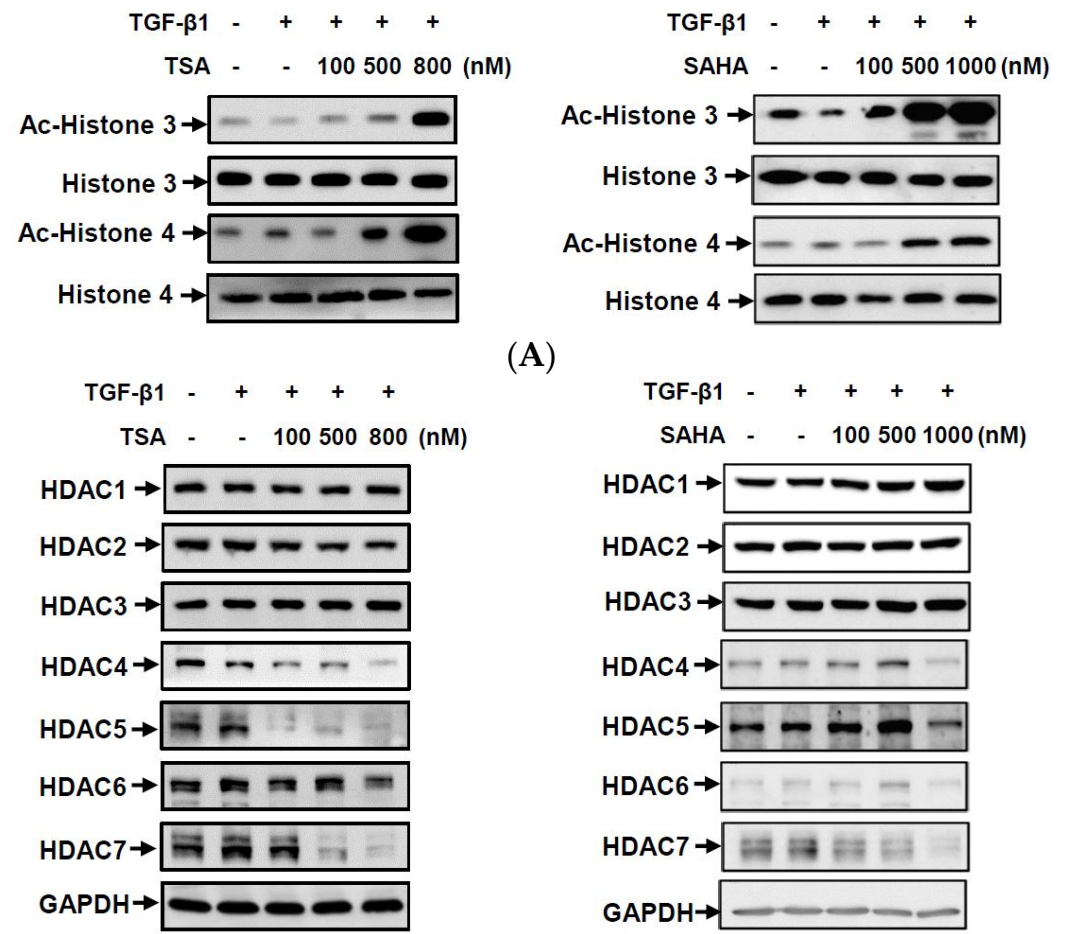

(A)

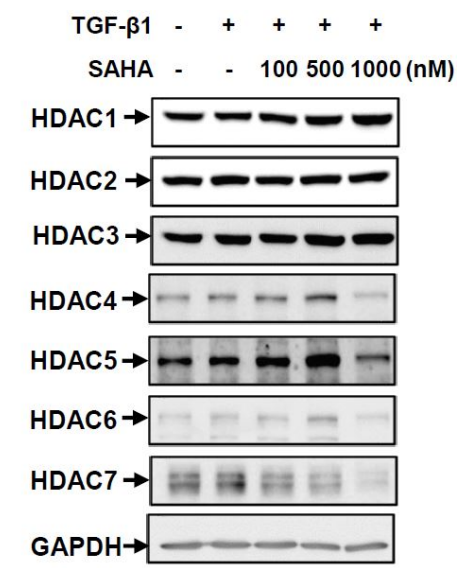

(B)

Figure 5. Histone deacetylase inhibitors (HDACis) downregulated class II HDAC member expressions and upregulated the acetylation of histones 3 and 4 in transforming growth factor (TGF)- $\beta 1$ treated chondrocytes. (A,B) Human primary chondrocytes (HC-a cells) were pretreated with different concentrations of trichostatin A (TSA) (100 800 nM) and vorinostat (SAHA) (100-1000 nM) for $30 \mathrm{~min}$ and then treated with $5 \mathrm{ng} / \mathrm{mL}$ TGF- $\beta 1$ for $24 \mathrm{~h}$. Total cellular proteins were collected, and protein expressions were detected by Western blotting. Ac, acetylated.
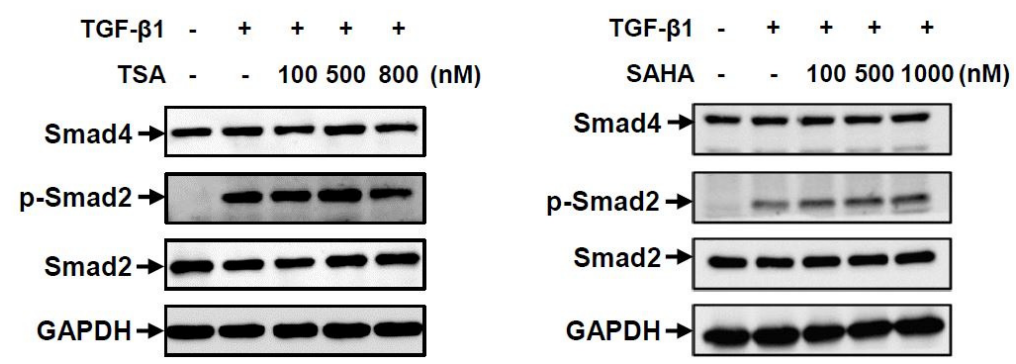

(A)

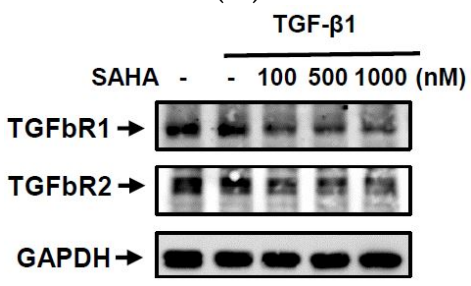

(B)

Figure 6. Histone deacetylase inhibitors (HDACis) did not affect Smad signal transduction in transforming growth factor (TGF)- $\beta 1$-treated chondrocytes. Human primary chondrocytes (HCa cells) were pretreated with different concentrations of trichostatin A (TSA) (100-800 nM) and vorinostat (SAHA) (100-1000 $\mathrm{nM}$ ) for $30 \mathrm{~min}$ and then treated with $5 \mathrm{ng} / \mathrm{mL}$ TGF- $\beta 1$ for (A) $2 \mathrm{~h}$ and (B) $24 \mathrm{~h}$. Total cellular proteins were collected, and protein expressions were detected by Western blotting. 


\section{Discussion}

TGF- $\beta 1$ is known to stimulate high ePPi production by increasing expressions of ANKH and ENPP1 in chondrocytes [37,38], but it reduces TNAP expression in human pulp cells [39]. In this study, we found that TGF- $\beta 1$ markedly induced mRNA expressions of $A N K H$ and ENPP1 but caused no significant change in TNAP mRNA expression in human primary cultured chondrocytes. These results are consistent with those reported in earlier research that used rat primary cultured chondrocytes [37]. When TGF- $\beta 1$ binds to its receptor, the receptor complex activates Smad transcription factors and non-Smad molecules, such as extracellular signal-regulated kinase (ERK). However, TSA and SAHA did not change the phosphorylation level of Smad-2 (Figure 6A) or ERK (data not shown), indicating that the HDACis were unable to affect signal transduction induced by TGF- $\beta 1$. Interestingly, TSA and SAHA significantly decreased TGF- $\beta$ RI and TGF- $\beta$ RII receptor expressions. These results suggest that HDACis might modulate expressions of ANKH, ENPP1, TNAP, and TGF- $\beta$ receptors at the level of epigenetic regulation, such as the acetylation status. However more experiments are needed to confirm whether HDACis change these gene expressions by increasing histone acetylation. Mechanical loading is known to change the transient and long-term metabolism of chondrocytes and plays an important role in cartilage integrity [40,41]. A previous study in an experimental model of porcine chondrocytes showed that ATP released by mechanical loading is the major source of pyrophosphate [42]. Mechanical strain increases the expression of ANK, ENPP1, and TGF- $\beta 1$ in rat chondrocytes [43]. In this study, we did not use the mechanical loading model, but HDACis reduced the gene expression of $A N K H$ and ENPP1 (Figures 1 and 2). Therefore we speculated that HDACis might also reduce mechanical-loading-induced pyrophosphate.

Previous studies showed that ANKH, ENPP1, and TNAP can regulate ePPi levels, among which ANKH is the most important regulator. In addition to exporting PPi, ANKH is responsible for exporting ATP. High levels of $A N K H$ mRNA were found in chondrocytes and cartilage extracts of CPPD patients [44]. ANKH gene mutations or polymorphisms were also related to CPPD [13,45]. High ePPi levels also contribute to bone hypermineralization, which is associated with OA disease. Calcium-containing crystals, including CPP, are common in joints and cartilage of OA patients [46], and their presence is related to OA severity [47]. Meniscal cells obtained from OA patients are easy to calcify, and calcificationrelated genes, such as ENPP1 and $A N K H$, also increase [48]. However, whether calciumcontaining crystals cause OA remains to be studied in depth.

HDACs are involved in the regulation of chondrocyte proliferation, maturation, and hypertrophy and are related to protecting cartilage. In recent years, however, several studies showed that HDACs contribute to the pathogenesis of OA [49]. In the early stage of mouse bone development, HDAC3 is necessary for chondrocyte maturation, but HDAC3 also activates expressions of matrix metalloproteinase 13 (MMP13) and a disintegrin-like metalloproteinase with thrombospondin 5 (ADAMTS5) via the nuclear factor (NF)- $\mathrm{kB}$ pathway and aggravates OA progress [50]. A study also found that cartilage of OA patients exhibited increased HDAC1 expression, which promoted activity of the Snail 1 transcription factor. Snail 1 is known as a repressor of collagen 2 gene expression in chondrocytes [51]. On the other hand, an HDACi exhibited protective activity in cartilage in several in vitro and in vivo models. TSA inhibited inducible nitric oxide (iNOS) and cyclooxygenase (COX)-2 expressions induced by IL-1 $\beta$ in chondrocytes [52] and improved OA through activation of the nuclear factor erythroid 2-related factor 2 (Nrf2) signal pathway in animals [53]. SAHA, like TSA, can also inhibit inflammation in chondrocytes. It inhibits expressions of MMPs and iNOS by inhibiting mitogen-activated protein kinase (MAPK) and NF- $\mathrm{KB}$ [54]. In this study, we found that both TSA and SAHA decreased extracellular ePPi levels and CPP formation in human primary cultured chondrocytes. These results suggest that the HDACis, TSA and SAHA, might block both CPP crystal formation and OA pathogenesis; therefore, HDACis could be developed as potential drugs to treat or prevent OA.

Previous studies showed that $\mathrm{CPG}$ island hypermethylation of gene promoter region, histone deacetylation, and histone $\mathrm{H} 3 \mathrm{~K} 9$ methylation are positively correlated to gene si- 
lencing. HDACis may remove methyl-binding proteins (MePC2) from methylated cytosines and then recruit histone acetyltransferase to re-acetylate histones. The hyperacetylation of histones may further attract DNA demethylase to remove methyl groups, which results in turning on or turning off gene expressions during this process [55]. Using CpG Island Finder (http:/ / dbcat.cgm.ntu.edu.tw /, accessed on 19 October 2021), we found that the gene promoters of $A N K H, E N P P 1$, and TNAP all possess CpG islands in the promoter region. It is possible that the HDACis, TSA and SAHA, might affect gene expressions of $A N K H, E N P P 1$, and TNAP by changing patterns of methylation and histone acetylation.

Previous studies [56] and the micro (mi)RNA database of SM2miR [57] showed that HDACis can regulate gene expressions through miRNAs. On the other hand, gene expressions of $A N K H, E N P P 1$, and TNAP are also regulated by many miRNAs according to the GeneCards database. For example, the SM2miR database showed that TSA might change expressions of miR-106b, miR-20a, miR-20b, miR-335, and miR-93, and the GeneCards database showed that these miRNAs might regulate expression of the $A N K H$ gene. Therefore, the HDACis, TSA and SAHA, can very likely regulate ANKH, ENPP1, and TNAP gene expressions by regulating miRNA expressions.

Currently, there is no drug to prevent or eliminate CPP formation. SAHA has been approved by the US Food and Drug Administration (FDA) to treat cutaneous T cell lymphoma, while its treatment of other cancers is being assessed in preclinical and clinical trials. In this study, we concluded that the HDACis, TSA and SAHA, were able to decrease ePPi and CPP formation by regulating ANKH, ENPP1, and TNAP expressions in human primary cultured chondrocytes. The underlying molecular mechanisms of HDACis-mediated regulation of ANKH, ENPP1, and TNAP expression might be associated with the histone acetylation status of the promoters of these three genes but not the TGF- $\beta$ /Smad pathway. HDACis have the potential to be developed into drugs to prevent CPP formation or treat CPP-related diseases in the future.

\section{Materials and Methods}

\subsection{Reagents}

Two kinds of class I and II HDACis, TSA and SAHA, were obtained from Union Biomed (Taipei, Taiwan); recombinant human TGF- $\beta 1$ was obtained from R\&D Systems (Minneapolis, MN, USA); the anti-ANKH and anti- $\alpha$-tubulin antibodies were obtained from Novus Biologicals (Littleton, CO, USA); the class I HDAC antibody sampler kit, class II HDAC antibody sampler kit, anti-Smad2, anti-phospho-Smad2 (Ser465/467), antihistone H3, anti-acetyl-histone H3-Lys9, and anti-acetylated-lysine (Ac-K-103) antibodies were obtained from Cell Signaling Technology (Beverly, MA, USA); the anti-ENPP1, antiTNAP, anti-acetyl-histone H4, anti-TGF- $\beta$ receptor I (TGFBR1), and anti-TGF- $\beta$ receptor II (TGFBR2) antibodies were obtained from Santa Cruz Biotechnology (Santa Cruz, CA, USA); and the anti-glyceraldehyde 3-phosphate dehydrogenase (GAPDH), anti-mouse immunoglobulin $\mathrm{G}(\mathrm{IgG})$ horseradish peroxidase (HRP), and anti-rabbit IgG HRP antibodies were obtained from GeneTex International (Hsinchu City, Taiwan).

\subsection{Cell Culture}

Human primary cultured articular chondrocytes (HC-a cells) were purchased from ScienCell Research Laboratories (Carlsbad, CA, USA), as well as an ethical approval document to ensure that there was no ethical issue when using HC-a cells for experiments. The cells were cultured in chondrocyte medium (CM), which included $1 \%$ chondrocyte growth supplement, $5 \%$ fetal bovine serum (FBS), and 1\% penicillin/streptomycin, on dishes coated with poly-L-lysine.

\subsection{Real-Time Reverse-Transcription Polymerase Chain Reaction (RT-PCR)}

Total RNA was isolated with a PureLink RNA Mini Kit (Invitrogen, Taipei, Taiwan), and complementary (c)DNA was synthesized using a high-capacity cDNA reversetranscription kit (Applied Biosystems, Taipei, Taiwan). Primer sequences of specific genes 
for the real-time PCR were: ANKH forward 5'-GCAGCCCACATCAAGAAGTT-3' and reverse $5^{\prime}$-TCCAAAACATCACGAAACAGA-3'; ENPP1 forward 5'-AGACAAGATGGGCAT GGAAC- $3^{\prime}$ and reverse $5^{\prime}$-AAAAGTGAAGGGGGTAACAGC-3 ${ }^{\prime}$; TNAP forward $5^{\prime}$-CCTGC CTTACTAACTCCTTAGTGC-3' ${ }^{\prime}$ and reverse $5^{\prime}$-CGTTGGTGTTGAGCTTCTGA-3 ${ }^{\prime}$; and GAPDH forward $5^{\prime}$-ATGACATCAAGAAGGTGGTG- $3^{\prime}$ and reverse $5^{\prime}$-CATACCAGGAAA TGAGCTTG-3'. Each real-time PCR used $2 \mathrm{ng}$ of cDNA, $200 \mathrm{nM}$ of forward and reverse primers, and $10 \mu \mathrm{L}$ of Fast SYBR Green Master Mix (Applied Biosystems) to a final volume $20 \mu \mathrm{L}$. The real-time PCRs were carried out on a StepOne real-time PCR system (Applied Biosystems). The real-time PCR conditions were $95^{\circ} \mathrm{C}$ pre-incubation for $30 \mathrm{~s} ; 40$ cycles of $95^{\circ} \mathrm{C}$ for $3 \mathrm{~s}$ and $60{ }^{\circ} \mathrm{C}$ for $30 \mathrm{~s}$ for amplification; and $95^{\circ} \mathrm{C}$ for $15 \mathrm{~s}, 60^{\circ} \mathrm{C}$ for $1 \mathrm{~min}$, and $95^{\circ} \mathrm{C}$ for $15 \mathrm{~s}$ for melting curve analysis. Messenger $(\mathrm{m}) \mathrm{RNA}$ levels were calculated by the comparative CT method, for which the CT value of mRNA was normalized to GAPDH [58].

\subsection{Western Blot Analysis}

Total cellular proteins $(20-50 \mu \mathrm{g})$ were heated to $100{ }^{\circ} \mathrm{C}$ for $5 \mathrm{~min}$ with a quarter volume of Laemmli buffer (4\% sodium dodecyl sulfate (SDS), 20\% glycerol, 10\% 2-mercaptoethanol, $0.004 \%$ bromophenol blue, and $0.125 \mathrm{M}$ Tris $\mathrm{HCl}$ at $\mathrm{pH} 6.8$ ), separated by $10 \%$ SDSpolyacrylamide gel electrophoresis (PAGE), and then transferred to polyvinylidene fluoride (PVDF) membranes (GE Healthcare Life Sciences, Taipei, Taiwan). The PVDF membranes were blocked in blocking buffer $(5 \%(w / v)$ skimmed milk powder in phosphate-buffered saline (PBS) $/ 0.1 \%$ Tween 20) and probed overnight with various primary antibodies, then with a second antibody conjugated with HRP. The specific protein bands were visualized with an ECL Western blotting substrate (Thermo Fisher Scientific, Taipei, Taiwan) in an ImageQuant LAS 4000 biomolecular imager (GE Healthcare Life Sciences, Marlborough, MA, USA) [59].

\subsection{ENPP1 and TNAP Colorimetric Activity Assays}

HC-a cells were collected and dissolved in a buffer containing 1\% Triton X-100, $1.6 \mathrm{mM}$ $\mathrm{MgCl}_{2}$, and $0.2 \mathrm{M}$ Tris Base ( $\mathrm{pH} 8.1$ ). An equal amount of cell lysate was added to $5 \mathrm{mM}$ of artificial substrates: thymidine $5^{\prime}$-monophosphate p-nitrophenyl ester (p-nitrophenyl-TMP, p-NpTMP) (Sigma, St Louis, MO, USA) for ENPP1 activity; and p-nitrophenyl phosphate (p-NPP) (MedChemExpress, Monmouth Junction, NJ, USA) for TNAP activity [37]. The reactions were performed on a SpectraMax iD3 multi-mode microplate reader (Molecular Devices, San Jose, CA, USA), and the absorbance was measured at $410 \mathrm{~nm}$ every $10 \mathrm{~min}$ for $2.5 \mathrm{~h}$.

\subsection{Extracellular Pyrophosphate (ePPi) Assay}

Culture medium was collected, and the ePPi level was detected using a PPi assay kit (BioVision, Milpitas, CA, USA) according to the manufacturer's instructions. The fluorescence signal was quantified using a SpectraMax iD3 multi-mode microplate reader (Molecular Devices) at an excitation wavelength of $535 \mathrm{~nm}$ and emission wavelength of $587 \mathrm{~nm}$.

\subsection{CPP Crystal Staining Assay}

High-density HC-a cells were seeded on 96-well plates at $10^{5}$ cells / well. Cells were treated with increasing concentrations of TSA or SAHA for $30 \mathrm{~min}$ and then treated with $5 \mathrm{ng} / \mathrm{mL}$ TGF- $\beta 1$ for 5 days. Cells were fixed in 10\% formalin and stained with $40 \mathrm{mM}$ Alizarin Red S (ARS) dye ( $\mathrm{pH} 4.1$ ) for calcium mineral deposition. After extensive washing with water, the remaining dye was extracted with $10 \%$ acetic acid and quantified by a SpectraMax iD3 multi-mode microplate reader (Molecular Devices) at $405 \mathrm{~nm}$ absorbance [60].

\subsection{Statistical Analysis}

Experimental data were evaluated by a one-way analysis of variance (ANOVA) followed by Tukey's post hoc test (Prism 7.0a, GraphPad Software San Diego, CA, USA). Data 
are presented as the mean \pm standard error (SE) of at least three independent experiments. $p<0.05$ was considered statistically significant.

Author Contributions: Conceptualization, C.-C.C. (Chi-Ching Chang) and Y.-C.L.; methodology, K.-L.L. and C.-C.C. (Chia-Chen Chung); data curation, Y.-C.L.; writing-original draft preparation, Y.-C.L. and C.-C.C. (Chi-Ching Chang); writing-review and editing, T.-S.C.; funding acquisition, C.-C.C. (Chi-Ching Chang), T.-S.C. and Y.-C.L. All authors have read and agreed to the published version of the manuscript.

Funding: This research was funded by the Ministry of Science and Technology of the Republic of China, grant number MOST 107-2320-B-038-023-MY3 and MOST 108-2314-B-038-058; Taipei Medical University Hospital, grant number 108TMU-TMUH-23; and Wan Fang Hospital, grant number 110TMU-WFH-11.

\section{Institutional Review Board Statement: Not applicable.}

Informed Consent Statement: Not applicable.

Data Availability Statement: The data presented in this study are available on request from the corresponding author.

Conflicts of Interest: The authors declare no conflict of interest.

\section{References}

1. McCarthy, G.M.; Dunne, A. Calcium crystal deposition diseases-Beyond gout. Nat. Rev. Rheumatol. 2018, 14, 592-602. [CrossRef] [PubMed]

2. Sidari, A.; Hill, E. Diagnosis and Treatment of Gout and Pseudogout for Everyday Practice. Prim. Care 2018, 45, 213-236. [CrossRef] [PubMed]

3. Zhang, Y.; Brown, M.A. Genetic studies of chondrocalcinosis. Curr. Opin. Rheumatol. 2005, 17, 330-335. [CrossRef] [PubMed]

4. Rachow, J.W.; Ryan, L.M. Adenosine triphosphate pyrophosphohydrolase and neutral inorganic pyrophosphatase in pathologic joint fluids. Elevated pyrophosphohydrolase in calcium pyrophosphate dihydrate crystal deposition disease. Arthritis Rheum. 1985, 28, 1283-1288. [CrossRef] [PubMed]

5. Rosenthal, A.K. Crystals, inflammation, and osteoarthritis. Curr. Opin. Rheumatol. 2011, 23, 170-173. [CrossRef] [PubMed]

6. Yashiro, T.; Okamoto, T.; Tanaka, R.; Ito, K.; Hara, H.; Yamashita, T.; Kanaji, Y.; Kodama, T.; Ito, Y.; Obara, T.; et al. Prevalence of chondrocalcinosis in patients with primary hyperparathyroidism in Japan. Endocrinol. Jpn. 1991, 38, 457-464. [CrossRef]

7. Joshi, A.; Siva, C. Magnesium disorders can cause calcium pyrophosphate deposition disease: A case report and literature review. Eur. J. Rheumatol. 2018, 5, 53-57. [CrossRef] [PubMed]

8. Mitton-Fitzgerald, E.; Gohr, C.M.; Williams, C.M.; Rosenthal, A.K. Identification of Common Pathogenic Pathways Involved in Hemochromatosis Arthritis and Calcium Pyrophosphate Deposition Disease: A Review. Curr. Rheumatol. Rep. 2022, $24,40-45$. [CrossRef]

9. Danino, O.; Svetitsky, S.; Kenigsberg, S.; Levin, A.; Journo, S.; Gold, A.; Drexler, M.; Snir, N.; Elkayam, O.; Fischer, B.; et al. Inhibition of nucleotide pyrophosphatase/phosphodiesterase 1: Implications for developing a calcium pyrophosphate deposition disease modifying drug. Rheumatology 2018, 57, 1472-1480. [CrossRef]

10. Johnson, K.; Hashimoto, S.; Lotz, M.; Pritzker, K.; Goding, J.; Terkeltaub, R. Up-regulated expression of the phosphodiesterase nucleotide pyrophosphatase family member PC-1 is a marker and pathogenic factor for knee meniscal cartilage matrix calcification. Arthritis Rheum. 2001, 44, 1071-1081. [CrossRef]

11. Williams, C.J. The role of ANKH in pathologic mineralization of cartilage. Curr. Opin. Rheumatol. 2016, 28, 145-151. [CrossRef] [PubMed]

12. Vollmayer, P.; Clair, T.; Goding, J.W.; Sano, K.; Servos, J.; Zimmermann, H. Hydrolysis of diadenosine polyphosphates by nucleotide pyrophosphatases/phosphodiesterases. Eur. J. Biochem. 2003, 270, 2971-2978. [CrossRef]

13. Abhishek, A.; Doherty, M. Pathophysiology of articular chondrocalcinosis-role of ANKH. Nat. Rev. Rheumatol. 2011, 7, 96-104. [CrossRef]

14. Costello, J.C.; Rosenthal, A.K.; Kurup, I.V.; Masuda, I.; Medhora, M.; Ryan, L.M. Parallel regulation of extracellular ATP and inorganic pyrophosphate: Roles of growth factors, transduction modulators, and ANK. Connect. Tissue Res. 2011, 52, 139-146. [CrossRef] [PubMed]

15. Derfus, B.A.; Camacho, N.P.; Olmez, U.; Kushnaryov, V.M.; Westfall, P.R.; Ryan, L.M.; Rosenthal, A.K. Transforming growth factor beta-1 stimulates articular chondrocyte elaboration of matrix vesicles capable of greater calcium pyrophosphate precipitation. Osteoarthr. Cartil. 2001, 9, 189-194. [CrossRef] [PubMed]

16. Lotz, M.; Rosen, F.; McCabe, G.; Quach, J.; Blanco, F.; Dudler, J.; Solan, J.; Goding, J.; Seegmiller, J.E.; Terkeltaub, R. Interleukin 1 beta suppresses transforming growth factor-induced inorganic pyrophosphate (PPi) production and expression of the PPigenerating enzyme PC-1 in human chondrocytes. Proc. Natl. Acad. Sci. USA 1995, 92, 10364-10368. [CrossRef] 
17. Ryan, L.M.; Rosenthal, A.K. Metabolism of extracellular pyrophosphate. Curr. Opin. Rheumatol. 2003, 15, 311-314. [CrossRef]

18. Heinkel, D.; Gohr, C.M.; Uzuki, M.; Rosenthal, A.K. Transglutaminase contributes to CPPD crystal formation in osteoarthritis. Front. Biosci. 2004, 9, 3257-3261. [CrossRef]

19. Rosenthal, A.K.; Masuda, I.; Gohr, C.M.; Derfus, B.A.; Le, M. The transglutaminase, Factor XIIIA, is present in articular chondrocytes. Osteoarthr. Cartil. 2001, 9, 578-581. [CrossRef]

20. Rosenthal, A.K.; Gohr, C.M.; Uzuki, M.; Masuda, I. Osteopontin promotes pathologic mineralization in articular cartilage. Matrix Biol. 2007, 26, 96-105. [CrossRef]

21. Kruhlak, M.J.; Hendzel, M.J.; Fischle, W.; Bertos, N.R.; Hameed, S.; Yang, X.J.; Verdin, E.; Bazett-Jones, D.P. Regulation of global acetylation in mitosis through loss of histone acetyltransferases and deacetylases from chromatin. J. Biol. Chem. 2001, 276, 38307-38319. [CrossRef]

22. Buchwald, M.; Krämer, O.H.; Heinzel, T. HDACi-Targets beyond chromatin. Cancer Lett. 2009, 280, 160-167. [CrossRef]

23. Drysdale, M.J.; Brough, P.A.; Massey, A.; Jensen, M.R.; Schoepfer, J. Targeting Hsp90 for the treatment of cancer. Curr. Opin. Drug Discov. Devel. 2006, 9, 483-495. [PubMed]

24. Choudhary, C.; Kumar, C.; Gnad, F.; Nielsen, M.L.; Rehman, M.; Walther, T.C.; Olsen, J.V.; Mann, M. Lysine acetylation targets protein complexes and co-regulates major cellular functions. Science 2009, 325, 834-840. [CrossRef] [PubMed]

25. Haberland, M.; Montgomery, R.L.; Olson, E.N. The many roles of histone deacetylases in development and physiology: Implications for disease and therapy. Nat. Rev. Genet. 2009, 10, 32-42. [CrossRef] [PubMed]

26. Xu, Y.; Hammerick, K.E.; James, A.W.; Carre, A.L.; Leucht, P.; Giaccia, A.J.; Longaker, M.T. Inhibition of histone deacetylase activity in reduced oxygen environment enhances the osteogenesis of mouse adipose-derived stromal cells. Tissue Eng. Part A 2009, 15, 3697-3707. [CrossRef]

27. Destaing, O.; Saltel, F.; Gilquin, B.; Chabadel, A.; Khochbin, S.; Ory, S.; Jurdic, P. A novel Rho-mDia2-HDAC6 pathway controls podosome patterning through microtubule acetylation in osteoclasts. J. Cell Sci. 2005, 118 Pt 13, 2901-2911. [CrossRef]

28. Huynh, N.C.; Everts, V.; Pavasant, P.; Ampornaramveth, R.S. Inhibition of Histone Deacetylases Enhances the Osteogenic Differentiation of Human Periodontal Ligament Cells. J. Cell Biochem. 2016, 117, 1384-1395. [CrossRef]

29. Huynh, N.C.; Everts, V.; Nifuji, A.; Pavasant, P.; Ampornaramveth, R.S. Histone deacetylase inhibition enhances in-vivo bone regeneration induced by human periodontal ligament cells. Bone 2017, 95, 76-84. [CrossRef]

30. Martinon, F.; Pétrilli, V.; Mayor, A.; Tardivel, A.; Tschopp, J. Gout-associated uric acid crystals activate the NALP3 inflammasome. Nature 2006, 440, 237-241. [CrossRef]

31. Liu-Bryan, R.; Pritzker, K.; Firestein, G.S.; Robert Terkeltaub, R. TLR2 signaling in chondrocytes drives calcium pyrophosphate dihydrate and monosodium urate crystal-induced nitric oxide generation. J. Immunol. 2005, 174, 5016-5023. [CrossRef] [PubMed]

32. Pang, L.; Hayes, C.P.; Buac, K.; Yoo, D.G.; Rada, B. Pseudogout-associated inflammatory calcium pyrophosphate dihydrate microcrystals induce formation of neutrophil extracellular traps. J. Immunol. 2013, 190, 6488-6500. [CrossRef] [PubMed]

33. Zhang, W.; Doherty, M.; Pascual, E.; Barskova, V.; Guerne, P.A.; Jansen, T.L.; Leeb, B.F.; Perez-Ruiz, F.; Pimentao, J.; Punzi, L.; et al. EULAR recommendations for calcium pyrophosphate deposition. Part II: Management. Ann. Rheum. Dis. 2011, 70, 571-575. [CrossRef] [PubMed]

34. Das, S.K.; Ramakrishnan, S.; Mishra, K.; Srivastava, R.; Agarwal, G.G.; Singh, R.; Sircar, A.R. A randomized controlled trial to evaluate the slow-acting symptom-modifying effects of colchicine in osteoarthritis of the knee: A preliminary report. Arthritis Rheum. 2002, 47, 280-284. [CrossRef]

35. Rothschild, B.; Yakubov, L.E. Prospective 6-month, double-blind trial of hydroxychloroquine treatment of CPDD. Compr. Ther. 1997, 23, 327-331.

36. Chollet-Janin, A.; Finckh, A.; Dudler, J.; Guerne, P.A. Methotrexate as an alternative therapy for chronic calcium pyrophosphate deposition disease: An exploratory analysis. Arthritis Rheum. 2007, 56, 688-692. [CrossRef]

37. Cailotto, F.; Bianchi, A.; Sebillaud, S.; Venkatesan, N.; Moulin, D.; Jouzeau, J.Y.; Netter, P. Inorganic pyrophosphate generation by transforming growth factor-beta-1 is mainly dependent on ANK induction by Ras/Raf-1/extracellular signal-regulated kinase pathways in chondrocytes. Arthritis Res. Ther. 2007, 9, R122. [CrossRef]

38. Rosen, F.; McCabe, G.; Quach, J.; Solan, J.; Terkeltaub, R.; Seegmiller, J.E.; Lotz, M. Differential effects of aging on human chondrocyte responses to transforming growth factor beta: Increased pyrophosphate production and decreased cell proliferation. Arthritis Rheum. 1997, 40, 1275-1281.

39. Shirakawa, M.; Shiba, H.; Nakanishi, K.; Ogawa, T.; Okamoto, H.; Nakashima, K.; Noshiro, M.; Kato, Y. Transforming growth factor-beta-1 reduces alkaline phosphatase mRNA and activity and stimulates cell proliferation in cultures of human pulp cells. $J$. Dent. Res. 1994, 73, 1509-1514. [CrossRef]

40. Guilak, F.; Meyer, B.C.; Ratcliffe, A.; Mow, V.C. The effects of matrix compression on proteoglycan metabolism in articular cartilage explants. Osteoarthr. Cartil. 1994, 2, 91-101. [CrossRef]

41. Lee, D.A.; Bader, D.L. Compressive strains at physiological frequencies influence the metabolism of chondrocytes seeded in agarose. J. Orthop. Res. 1997, 15, 181-188. [CrossRef] [PubMed]

42. Graff, R.D.; Lazarowski, E.R.; Banes, A.J.; Lee, G.M. ATP release by mechanically loaded porcine chondrons in pellet culture Arthritis Rheum. 2000, 43, 1571-1579. [CrossRef]

43. Xu, H.G.; Hu, C.J.; Wang, H.; Liu, P.; Yang, X.M.; Zhang, Y.; Wang, L.T. Effects of mechanical strain on ANK, ENPP1 and TGF- $\beta 1$ expression in rat endplate chondrocytes in vitro. Mol. Med. Rep. 2011, 4, 831-835. [CrossRef] [PubMed] 
44. Hirose, J.; Ryan, L.M.; Masuda, I. Up-regulated expression of cartilage intermediate-layer protein and ANK in articular hyaline cartilage from patients with calcium pyrophosphate dihydrate crystal deposition disease. Arthritis Rheum. 2002, 46, 3218-3229. [CrossRef] [PubMed]

45. Zhang, Y.; Johnson, K.; Russell, R.G.; Wordsworth, B.P.; Carr, A.J.; Terkeltaub, R.A.; Brown, M.A. Association of sporadic chondrocalcinosis with a -4-basepair G-to-A transition in the $5^{\prime}$-untranslated region of ANKH that promotes enhanced expression of ANKH protein and excess generation of extracellular inorganic pyrophosphate. Arthritis Rheum. 2005, 52, 1110-1117. [CrossRef]

46. Conway, R.; McCarthy, G.M. Calcium-Containing Crystals and Osteoarthritis: An Unhealthy Alliance. Curr. Rheumatol. Rep. 2018, 20, 13. [CrossRef]

47. Fuerst, M.; Bertrand, J.; Lammers, L.; Dreier, R.; Echtermeyer, F.; Nitschke, Y.; Rutsch, F.; Schäfer, F.K.; Niggemeyer, O.; Steinhagen, J.; et al. Calcification of articular cartilage in human osteoarthritis. Arthritis Rheum. 2009, 60, 2694-2703. [CrossRef]

48. Sun, Y.; Mauerhan, D.R.; Honeycutt, P.R.; Kneisl, J.S.; Norton, H.J.; Zinchenko, N.; Hanley, E.N., Jr.; Gruber, H.E. Calcium deposition in osteoarthritic meniscus and meniscal cell culture. Arthritis Res. Ther. 2010, 12, R56. [CrossRef]

49. Zhang, H.; Ji, L.; Yang, Y.; Zhang, X.; Gang, Y.; Bai, L. The Role of HDACs and HDACi in Cartilage and Osteoarthritis. Front. Cell Dev. Biol. 2020, 8, 560117. [CrossRef]

50. Carpio, L.R.; Bradley, E.W.; McGee-Lawrence, M.E.; Weivoda, M.M.; Poston, D.D.; Dudakovic, A.; Xu, M.; Tchkonia, T.; Kirkland, J.L.; van Wijnen, A.J.; et al. Histone deacetylase 3 supports endochondral bone formation by controlling cytokine signaling and matrix remodeling. Sci. Signal. 2016, 9, ra79. [CrossRef]

51. Hong, S.; Derfoul, A.; Pereira-Mouries, L.; Hall, D.J. A novel domain in histone deacetylase 1 and 2 mediates repression of cartilage-specific genes in human chondrocytes. FASEB J. 2009, 23, 3539-3552. [CrossRef]

52. Chabane, N.; Zayed, N.; Afif, H.; Mfuna-Endam, L.; Benderdour, M.; Boileau, C.; Martel-Pelletier, J.; Pelletier, J.P.; Duval, N.; Fahmi, H. Histone deacetylase inhibitors suppress interleukin-1beta-induced nitric oxide and prostaglandin E2 production in human chondrocytes. Osteoarthr. Cartil. 2008, 16, 1267-1274. [CrossRef] [PubMed]

53. Cai, D.; Yin, S.; Yang, J.; Jiang, Q.; Cao, W. Histone deacetylase inhibition activates Nrf2 and protects against osteoarthritis. Arthritis Res. Ther. 2015, 17, 269. [CrossRef] [PubMed]

54. Zhong, H.M.; Ding, Q.H.; Chen, W.P.; Luo, R.B. Vorinostat, a HDAC inhibitor, showed anti-osteoarthritic activities through inhibition of iNOS and MMP expression, p38 and ERK phosphorylation and blocking NF- $\mathrm{B}$ nuclear translocation. Int. Immunopharmacol. 2013, 17, 329-335. [CrossRef]

55. Vaissière, T.; Sawan, C.; Herceg, Z. Epigenetic interplay between histone modifications and DNA methylation in gene silencing Mutat. Res. 2008, 659, 40-48. [CrossRef]

56. Scott, G.K.; Mattie, M.D.; Berger, C.E.; Benz, S.C.; Benz, C.C. Rapid alteration of microRNA levels by histone deacetylase inhibition. Cancer Res. 2006, 66, 1277-1281. [CrossRef] [PubMed]

57. Liu, X.; Wang, S.; Meng, F.; Wang, J.; Zhang, Y.; Dai, E.; Yu, X.; Li, X.; Jiang, W. SM2miR: A database of the experimentally validated small molecules' effects on microRNA expression. Bioinformatics 2013, 29, 409-411. [CrossRef]

58. Suk, F.M.; Chang, C.C.; Lin, R.J.; Lin, S.Y.; Liu, S.C.; Jau, C.F.; Liang, Y.C. ZFP36L1 and ZFP36L2 inhibit cell proliferation in a cyclin D-dependent and p53-independent manner. Sci. Rep. 2018, 8, 2742. [CrossRef] [PubMed]

59. Suk, F.M.; Chang, C.C.; Sun, P.C.; Ke, W.T.; Chung, C.C.; Lee, K.L.; Chan, T.S.; Liang, Y.C. MCPIP1 Enhances TNF- $\alpha$-Mediated Apoptosis through Downregulation of the NF- $\mathrm{BB} / \mathrm{cFLIP}$ Axis. Biology 2021, 10, 655. [CrossRef]

60. Chang, C.C.; Tsai, Y.H.; Liu, Y.; Lin, S.Y.; Liang, Y.C. Calcium-containing crystals enhance receptor activator of nuclear factor $\kappa B$ ligand/macrophage colony-stimulating factor-mediated osteoclastogenesis via extracellular-signal-regulated kinase and p38 pathways. Rheumatology 2015, 54, 1913-1922. [CrossRef] [PubMed] 